\title{
Engineering and Development of Chitosan-based Nanocoatings for Ocular Contact Lenses
}

Prina Mehta ${ }^{a}$, Ali A. Al-Kinani ${ }^{b}$, Muhammad Sohail Arshad $^{a}$, Neenu Singh ${ }^{a}$, Susanna M. van der Merwe ${ }^{c}$ Ming-Wei Chang d,e, Raid G. Alany ${ }^{\mathrm{b}, \mathrm{f}}$, Zeeshan Ahmad ${ }^{\mathrm{a}}$,

a The Leicester School of Pharmacy, De Montfort University, Leicester, LE1 1BH, UK

${ }^{\mathrm{b}}$ School of Life Sciences, Pharmacy and Chemistry, Kingston University London, Kingston Upon Thames, KT1 2EE, UK

c School of Pharmacy and Biomedical Sciences, University of Portsmouth, Portsmouth, PO1 2DT, UK.

${ }^{d}$ College of Biomedical Engineering and Instrument Science, Zhejiang University, Hangzhou 310027, China

e Zhejiang Provincial Key Laboratory of Cardio-Cerebral Vascular Detection Technology and Medicinal Effectiveness Appraisal, Zhejiang University, Hangzhou 310027, China

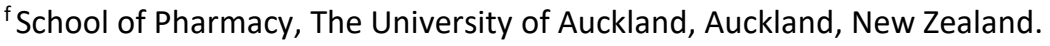

*Authors for correspondence

Prof. Raid Alany, R.Alany@kingston.ac.uk

Prof. Zeeshan Ahmad, zahmad@dmu.ac.uk 


\section{Abstract}

This research manuscript reports on Electrohydrodynamic Atomisation (EHDA) to engineer ondemand coatings for ocular contact lenses. A formulation approach was adopted to modulate the release of timolol maleate (TM) using chitosan and borneol. Polyvinylpyrrolidone (PVP) and poly (Nisopropylacrylamide) (PNIPAM) were electrically atomised to produce optimised, stationary contact lens coatings to encapsulate TM. The particle and fibre diameter, thermal stability, compatibility of the formed coatings along with their in vitro release-modulating effect and ocular tolerability were investigated. The results demonstrated highly stable nano-matrices with advantageous morphology and size. All formulations yielded coatings with high TM encapsulation (>88\%); with excellent ocular biocompatibility. The coatings presented biphasic and triphasic release; depending on composition. Kinetic modelling revealed a noticeable effect of chitosan; the higher the concentration, the more the TM release due to chitosan swelling; with the release mechanism changing from Fickian diffusion (1\% $w / v ; n=0.5)$ to non-Fickian ( $5 \% w / v, 0.45<n<0.89)$. The use of EHDA has not yet been explored in depth within the ocular research remit; engineering on demand lens coatings capable of sustaining TM release. This is likely to offer an alternative dosage form for management of glaucoma with particular emphasis on improving poor patient compliance. 


\section{Introduction}

The anatomy of the cornea significantly affects drug transit into the eye (Taskar, Tatke et al. 2017) . This transparent membrane makes up $7-10 \%$ of the whole eye, works predominantly to protect the front of the eye, and provides a majority of the optical focussing power; focusing any light that enters the eye. The cornea is a multi-layered tissue; $11 \mathrm{~mm}$ in diameter; consisting of 5 layers. The various degrees of hydrophilicity across the cornea due to the composition of these 5 layers hinder drug molecule movement through the cornea. As a result of this, there are two main mechanisms of transport drug molecules can take; the paracellular or transcellular pathway. Paracellular movement involves the drug molecules passing through the cornea via the tight junctions (Al-Kinani, Zidan et al. 2018). This mode of transport is often unlikely in corneal drug delivery due to the cellular arrangement of the outer corneal epithelium. A majority of ocular drugs are too large (<100Da) to pass to and across Bowman's. Paracellular movement is possible through the stroma but as a result of its hydrophilic nature, transport is limited to only polar molecules. Hydrophilic molecules can also pass through pores in the epithelial layer but larger molecules are often limited by tight junctions. On the other hand, transcellular movement through a membrane is based on diffusive methods or partitioning into and within cell membranes (Mehta et al. 2017a). There are two main pathways for drug molecules to reach the anterior chamber behind the cornea. The first pathway, known as the lateral route, involves the drug molecule portioning from the hydrophilic stroma into the lipophilic endothelium followed by diffusion within the lipid rich endothelium and partitioning into the aqueous humor (AH). The alternate route, the transverse route entails partitioning of drug molecules out of the anterior cell membrane into the posterior cell membrane and diffusing out (Gaudana, Ananthula et al. 2010).

Due to a large majority of ocular drugs lacking amphiphilic properties; they are unable to pass through all 5 layers of the cornea. As a result of this, there have been various attempts to bypass this anatomical barrier; the most common being the use of permeation enhancers (Mehta, Al-Kinani et al. 2017). The incorporation of permeation enhancers into ocular formulations could modulate drug release and absorption; in turn improving ocular bioavailability.

As a result of material development, and exponential increase in research in this remit, certain polymers have been found to possess release modulating and permeation enhancing capabilities. Chitosan is a primary example of these "modern release modulators and permeation enhancers" (Kumar, Vimal et al. 2016). This cationic polysaccharide has gained particular interest due to its 
mucoadhesiveness and low toxicity (Mahaling, Katti 2016, Muxika, Etxabide et al. 2017). Consequently, chitosan does not disrupt or compromise the corneal epithelial. It is thought the cationic nature of chitosan interacts with the cell membranes; disrupting tight junction proteins; hence enhancing paracellular drug transport (Kumar et al. 2016); which may also impose some toxicity. Furthermore, the sol-gel transformation of chitosan tends to affect drug release.

Chitosan has previously been utilised as a release modulator and PE for an array of biological membranes including buccal tissue (Duttagupta, Jadhav et al. 2015, Kontogiannidou, Andreadis et al. 2017), intestinal tissue (Chougule, Patel et al. 2014, Maher, Mrsny et al. 2016, Ates, Kaynak et al. 2016), nasal cavity (Benediktsdottir, Baldursson et al. 2014, Giuliani, Balducci et al. 2018). Chitosan has also been scrutinised in the ocular drug delivery due to its permeation enhancement properties; with drugs such as ofloxacin (Di Colo, Burgalassi et al. 2004), triamcinolone acetonide (Raval, Khunt et al. 2018) and timolol maleate (Rodriguez, Antonio Vazquez et al. 2017). Most studies demonstrated an enhanced ex vivo permeation of drug upon incorporation of chitosan or chitosan derivatives (Rupenthal, Green et al. 2011).

Borneol is a naturally occurring essential oil of Cinnamonum camphora. Although it does not fit into a defined category of permeation enhancers, it has shown potential in promoting corneal permeation of ocular the drugs TM (Wu Chun-Jie, Huang Qin-Wan et al. 2006), dexamethasone (Yang, Xun et al. 2009), indomethacin (Yang et al. 2009) and ofloxacin (Yang et al. 2009).

The effects of chitosan and borneol on drug release when incorporated into TM-loaded-polymeric coatings for contact lenses was assessed. Electrohydrodynamic atomisation (EHDA) was used to develop electrically atomised coatings using two polymers, polyvinylpyrrolidone (PVP) and poly (Nisopropylacrylamide) (PNIPAM) and anti-glaucoma drug TM. EHDA is a highly advantageous method for yielding nanoparticles of various morphologies (Zhang, Yao et al. 2017). The one-step, on- demand process is easily amenable and easy to operate; enabling the user to modify the process to meet any specific prerequisites or criteria (Wang, Zheng et al. 2017). Electrohydrodynamic (EHD) processing has already shown great promise in interacting with bio-interfaces (Zamani, Prabhakaran et al. 2013, Xie, Jiang et al. 2015, Mehta et al. 2017b); and with the exponential increase in the interest and development of materials in recent years, it is now possible to produce electrically atomised structures which are able to alter the release of drug in a controlled manner over a specified/personalised period.

EHDA has not yet been thoroughly exploited in the ocular drug delivery remit and only in recent years has the potential of using EHDA for ocular application been recognised, with researchers producing 
fibrous structures for not only drug delivery but corneal tissue engineering. Lancina et al developed electrospun dendrimer nanofibers as a matrix to delivery anti-glaucoma drug brimonidine tartrate topically to the cornea (Lancina et al., 2017). Whilst IOP responses were similar between this developed system and pure drug solution, in a single dose test the dendrimer fibers demonstrated much improved efficacy over 3 weeks. This, along with the fibers exhibiting no toxicity or ocular irritation, indicates the great potential these electrospun fibers have as vehicles for topical ocular drug delivery. Polycaprolactone (PCL) has been used as a fibrous matrix to delivery antibiotic ofloxacin for the treatment of ocular infections (Karatas et al., 2016). The resulting fibres provided burst release of the drug and showed sufficient microbiological activity against both gram positive and gram negative bacteria. The potential of using ES for ocular inserts has also been scrutinised and compared to the technique of solvent casting (Bhattarai et al., 2017). The electrospun fibers were found to be much thinner $(1 \%$ PVA $=50 \mu \mathrm{m}, 5 \%$ PVA $=62.5 \mu \mathrm{m})$ than brittle solvent cast polymer inserts $(>200 \mu \mathrm{m})$ and were capable of releasing drug in a sustained manner.

The research presented herwithe will delve into the possibility of modifying polymeric formulations to modulate the release of TM which will hopefully promote better corneal absorption. The development of a contact lens to deliver TM over extended periods of time is of clinical significance for management of glaucoma in the elderly population where compliance is poor with conventional TM eye drops.

\section{Materials and Methods}

\section{Materials}

PVP $\left(4.4 \times 10^{4} \mathrm{~g} / \mathrm{mol}\right)$ was obtained from Ashland, UK. PNIPAM $\left(2-4 \times 10^{4} \mathrm{~g} / \mathrm{mol}\right)$, chitosan ethanol, (TM) ( $>98 \%)$, acetone, sodium hydroxide, Rhodamine $B$, and Borneol $(\mathrm{PE})$ were all purchased from Sigma Aldrich (Dorset, UK). PureVision ${ }^{\circledR}$ Balafilcon A silicone hydrogel contact lenses were supplied by Bausch and Lomb (New York, USA). All reagents used were of analytical grade.

\section{Methods}

\section{Timolol Maleate Calibration Curve}


A stock solution (SS1) was prepared by weighing $10 \mathrm{mg}$ of TM on an analytical balance and dissolving this in $100 \mathrm{ml}$ of freshly prepared phosphate buffer saline (PBS) at pH 7.4.10 ml was taken from SS1 and made up to $100 \mathrm{ml}$ to make a second stock solution (SS2).

Both stock solutions were used to achieve a range of TM concentrations from $0 \mu \mathrm{g} / \mathrm{ml}$ to $50 \mu \mathrm{g} / \mathrm{ml}$. UV spectroscopy was used to firstly determine the wavelength of maximum absorbance (in scanning mode) and then consequently to read the absorbance of the range of TM solutions (in fixed mode). A calibration curve of TM was plotted using these absorbance values (S1). Readings were taken in triplicate and an average was taken.

\section{Formulation Preparation}

A $5 \% \mathrm{w} / \mathrm{w}$ polymeric solution was prepared by dissolving $2.5 \% \mathrm{w} / \mathrm{w}$ PVP and $2.5 \% \mathrm{w} / \mathrm{w}$ PNIPAM in ethanol. This mixture was the base solution used to prepare a series of formulations (each 20ml) containing various concentrations of chitosan. Table 1 shows the composition of formulations. Each formulation also contained $15 \% \mathrm{w} / \mathrm{w}$ TM (with respect to polymer concentration). All solid excipients were weighed using an analytical balance and were mixed using a magnetic stirrer for 30 minutes to ensure homogeneity. One thing to note here is that chitosan is insoluble in ethanol, and therefore homogenous suspensions were formed.

\section{Coating Application}

Figure 1 shows a schematic diagram of the EHDA set-up used in this research. A BD Plastipak ${ }^{\mathrm{TM}}$ Luer syringe containing $5 \mathrm{~mL}$ of solution was mounted on to a Pump11 Elite syringe infusion pump (Harvard Apparatus, USA) which was used to precisely control the flow of polymer-drug solution through the EHDA system. The syringe was connected to BD Microlance ${ }^{\mathrm{TM}} 3$ needle (21G, $1 \frac{1 / 2}{2}$ inch) which in turn was inserted into silicone tubing. The formulation was infused through the tube to a stainless steel conductive coaxial needle device, where only the outer needle was used. The coaxial device was also coupled to a high power voltage supply from Glassman High Voltage Supply, UK. A collector plate was placed $12 \mathrm{~cm}$ under the needle exit; this was the working distance (determined via exploratory experiments). The formulations were infused at a rate of $10 \mu \mathrm{l} / \mathrm{min}$ at $17.8 \mathrm{kV}$. All atomisation processes were carried out at ambient temperatures; $23^{\circ} \mathrm{C}$. The resulting atomised coatings were initially collected on glass microscope slides for preliminary analysis; with following characterisation experiments carried out on coated commercial contact lenses. PureVision ${ }^{\circledR}$ Balafilcon A lenses were dried in a desiccator on a modified lens holder (to maintain lens shape) for 30 minutes and were 
weighed before and following the coating process to determine the weight of the coating sample. Controlled deposition of coating was achieved by using a modified lens holder (which held 4 lenses) with an additional mask arm which enabled deposition onto peripheral regions; keeping central regions clear for vision.

\section{Coating Characterisation}

\section{Drug Encapsulation and Coating Composition}

To determine TM encapsulation efficiency; freshly weighed coating samples were dissolved in ethanol for 24 hours. UV spectroscopy $(\lambda=295 \mathrm{~nm})$ was used to determine the amount of drug loaded into the weighed sample.

\section{Imaging and Size Distribution}

Exploratory analysis of morphology and size of the nanostructures that make up the atomised coatings were conducted using SEM. Coated microscope slides were gold-coated (S150B, Edwards, Crawley, UK) and mounted onto aluminium stubs before analysed using Zeiss Evo HD-15 microscope. Highresolution images at both $\times 5 \mathrm{k}$ and $\mathrm{x} 50 \mathrm{k}$ magnification were obtained using a working distance between $9.5 \mathrm{~mm}$ and $10.5 \mathrm{~mm}$, respectively, with a voltage between $10 \mathrm{kV}$ and $18 \mathrm{kV}$.

Smart Tiff viewer software was used in conjunction with SEM to gather data on average diameter size and size distribution information on the atomised structures. These samples were further analysed on contact lenses to ensure the lenses (i.e. the surface the coatings were collected on) did not affect the resulting atomised structures.

\section{FTIR Spectroscopy}

Any interactions between the polymers, TM and permeation enhancers was studied using ATR-FTIR. Spectras were obtained using FTIR Platinum-ATR spectrophotometer fitted with Bruker Alpha Opus 27 FT-IR Raw materials and atomised coatings were scanned over the range of $400-4000 \mathrm{~cm}^{-1}$ at an average of 10 scans with $4 \mathrm{~cm}^{-1}$ resolution at ambient temperatures.

\section{Goniometry}


The wetting ability of the coatings was quantitatively analysed using Thetalite TL100 contact angle

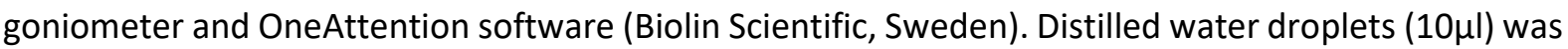
used and each sample was ran 5 times in Sessile Drop Mode and an average was taken.

\section{Differential Scanning Calorimetry}

Differential Scanning Calorimetry (DSC) studies were carried out using a Jade Differential Scanning Calorimeter, (PerkinElmer, US). Indium, with a known melting point, $\mathrm{Tm}$, of $156.6^{\circ} \mathrm{C}$ was used as a standard to calibrate the temperature scale of the calorimeter. Coating samples (2-4mg) were sealed in aluminium pans and heated at a rate of $20^{\circ} \mathrm{C} / \mathrm{min}$ under a flow of nitrogen gas.

\section{In Vitro Release}

A lens holder was designed and developed to carry the coated lens and to maximise contact surface between the lens and the synthetic dialysis membrane. The membrane separated the donor compartment from the receptor compartment, which contained PBS at $\mathrm{pH} 7.4$, which was placed in the receptor compartment and acted as the release medium (Figure 2). The coated lens were fixed into the holder and exposed to vials filled with $10 \mathrm{ml} \mathrm{PBS}$ at $37^{\circ} \mathrm{C}$. At fixed time intervals, the holder was removed and placed into fresh vials of PBS. This in vitro drug release method was adapted from Mehta et al (Mehta, Justo et al. 2015). Drug release into the medium was quantified straightaway following removal using UV spectroscopy $(\lambda=295 \mathrm{~nm})$. The mechanism of TM release from the polymeric coatings was determined by manipulating in vitro data and applying to various kinetic models.

Probe release was demonstrated using a similar set-up to the process described above. Contact lenses were coated with polymeric nanostructures containing rhodamine $B, 5 \% \mathrm{w} / \mathrm{w}$ of the polymer as opposed to TM. Five lenses were coated and exposed to PBS at $37^{\circ} \mathrm{C}$. Each lens was removed at specific predetermined time points: 0 minutes, 10 minutes, 1 hour, 6 hours and 24 hours. Fluorescence microscopy was used to determined dye intensity (DI) on the lens and UV spectroscopy to determine dye intensity in the receptor medium (PBS) at $\lambda=560$. Experiments were carried out in triplicate for all 3 formulations.

\section{Ocular Tolerability Testing}

Any damage the atomised coating could cause to the eye was evaluated using the BCOP (Bovine Corneal Opacity and Permeability) assay. This test can assess ocular tolerability via investigating the 
interference of the test material with corneal integrity. Samples were tested; normal saline (as a negative control), acetone (mild positive control), sodium hydroxide (positive control), F1, F2 and F3. Freshly excised bovine eyes (obtained from abattoirs ABP Food Group, Guildford, UK) were primarily checked for epithelial integrity and/or corneal damage and were then incubated at $37^{\circ} \mathrm{C}$ in a water bath for 10 minutes. Drop of saline was applied to the corneal surface before incubating for a further 5 minutes. $100 \mu \mathrm{l}$ of sample (control or formulation) was introduced to the corneal surface and left for 30 seconds before the bovine eyes were washed with normal saline $(10 \mathrm{ml})$ and left to incubate for a further 10 minutes. Degree of corneal damage was visually determined from the extent of opacification and was further assessed using a staining method; using sodium fluorescein dye $(2 \% \mathrm{w} / \mathrm{v})$ under a cobalt blue light (465-490 $\mathrm{nm})$.

\section{Statistical Analysis}

One way ANOVA test was carried to compare the release of TM from the atomised coatings. Derived $p$ values less than 0.5 were considered statistically significant. 


\section{Results and Discussion}

\section{Drug Encapsulation and Coating Composition}

Table 2 displays the final composition of the resulting coatings alongside encapsulation efficiency. The highest encapsulation was displayed by F1 (97.93\%) with F6 showing the lowest EE at $88.38 \%$. As the concentration of chitosan increases in the formulations containing borneol, the EE seems to reduce to 93.92\% (2\%w/w chitosan) and $90.69 \%$ (5\%w/w chitosan). This pattern was also observed with borneol-free samples. Saroha et al reported similar results with low concentrations of chitosan providing the maximum TM EE (75.34\%) when using ionic gelation to develop NPs for improved ocular drug delivery (Saroha, Pandey et al. 2017). Regardless of these reductions in EE, all formulations are considered to have achieved very high encapsulations of TM that are sufficient to administer a therapeutics dose.

\section{Imaging and Size Distribution}

The morphological effect of utilising chitosan in this study can be observed in Figure 3. Atomising Composite-TM formulations presented beaded fibres; as a result of inadequate gap between the needle exit and the collection plate. This could also be due to the combination of PVP and PNIPAM; polymers that usually yield particle and fibres when electrohydrodynamically processed separately (Figure 3). The addition of PE borneol yielded smooth-surfaced NFs with bell-shaped size distribution; an average of $74.30 \mathrm{~nm}$ in width: thinner than previously found when electrospinning borneol and PVP (Li, X., Wang, X., Yu et al. 2012). With respect to chitosan-loaded coatings, it is clear that there was a drastic morphological difference. Upon incorporating chitosan, the resulting atomised structures have now formed particles held together by scarce fibres. Figures $\mathbf{3 d} \mathbf{d} \mathbf{f}$ show the effect of chitosan concentration on the morphology of atomised coatings contained borneol. Figure 3g-i shows the effect of chitosan without borneol. It is evident that the use of chitosan as solid particles has increased the overall particle size and subsequently increased the particle size distribution. The chitosan particles may have been trapped inside PVP: PNIPAM matrices; hence increasing the overall size of the particles being produced. In the presence of borneol, there seems to be less particle/fibre aggregation; presumably due to the surface active agent properties of the borneol (Li, X., Wang, X. et al. 2012) .

Increasing chitosan concentration also had an impact on the morphology of the structures that made up the coatings. As concentration increased, the proportion of the final composition that is made up of PE decreased; reducing the fibrous network of the coatings. The smallest average diameter was 
$114.42 \mathrm{~nm}$ thick; achieved by electrospraying F1 with the highest being yielded by F6 $(919.65 \mathrm{~nm})$. Whilst there is such a large difference in the size distributions between these formulations, all formulations yielded coatings which consisted of structures well below $10 \mu \mathrm{m}$ in diameter; the threshold for the ocular tissue to detect the material as foreign bodies (Agrahari, Mandal et al. 2016). F1, F4 and F5 all demonstrated right-skewed distribution (Figure 4); with more than $44 \%$ of all particles produced being under $100 \mathrm{~nm}$. F2 and F6 showed negatively skewed data; highlighting at least $45 \%$ of the structures being more than $200 \mathrm{~nm}$ in diameter for both formulations. F3 showed a multimodal distribution; with $75 \%$ of the structures being over $200 \mathrm{~nm}, 15 \%$ under $100 \mathrm{~nm}$ and $9 \%$ between the range $100 \mathrm{~nm}$ and $200 \mathrm{~nm}$.

\section{FTIR Analysis}

With EHDA being an engineering process, it is important to ensure there is no incompatibility between the materials being processed. With chitosan being used as solid particles here, FTIR was employed to deduce any interactions between any of the excipients; dissolved or dispersed. Figure $\mathbf{5}$ displays the fingerprints for both raw materials and electrically atomised coatings. Pure TM shows characteristic peaks at $2968 \mathrm{~cm}^{-1}$ (aliphatic C-H stretching), $3063 \mathrm{~cm}^{-1}$, (aromatic C-H stretching), $1718 \mathrm{~cm}^{-1}(\mathrm{C}=\mathrm{O})$, $1229 \mathrm{~cm}^{-1}$ (O-H bending), $954 \mathrm{~cm}^{-1}$ (C-O stretching vibrations). The peak at $1651 \mathrm{~cm}^{-1}$ in all spectra for 6 formulations correspond to $\mathrm{C}=\mathrm{O}$ stretching vibrations in PVP whilst absorption peaks in the spectrum for PNIPAM were indicative of an amide II bond at $1500 \mathrm{~cm}^{-1}, \mathrm{C}=\mathrm{O}$ stretching and $\mathrm{CH}_{3}$ asymmetric stretching vibrations at $1650 \mathrm{~cm}^{-1}$ and $2970 \mathrm{~cm}^{-1}$, respectively. With regards to chitosan, the peak at $1636 \mathrm{~cm}^{-1}$ is due to $\mathrm{N}-\mathrm{H}$ bending of the free primary amine ( $\mathrm{NH}_{2}$ group) of the chitosan, whilst the peak $1028 \mathrm{~cm}^{-1}$ is as a result of $\mathrm{C}=0$ amide group stretching vibration. The stretching vibrations of the amino group gave rise to a peak at $1420 \mathrm{~cm}^{-1}$ and $\mathrm{O}-\mathrm{H}$ stretching and amine $\mathrm{N}-\mathrm{H}$ symmetric vibrations produced a peak at $3329 \mathrm{~cm}^{-1}$. These prominent peaks are also present in the fingerprints for all 6 formulations. No extreme shifts in the peaks can be detected showing the dissolved components had not interacted with the chitosan during the EHD process; i.e. no new bonds seemed to form between chitosan and the polymers or drug.

One thing to note here is the increase in peak intensity, which can be seen at $1710 \mathrm{~cm}^{-1}, 2964 \mathrm{~cm}^{-1}$, $1286 \mathrm{~cm}^{-1}$ and $3274 \mathrm{~cm}^{-1}$. This increase is indicative of mass increase as frequency of vibration is inversely proportional to mass. This could also be due to some of the chitosan being present outside of the atomised structures as opposed to being completely encapsulated (Merlini, Barra et al. 2014). 


\section{Thermal Analysis}

DSC

Figure 6 displays the DSC thermograms for F0-F6, with pure TM, raw chitosan and composite TM atomised coatings. Pure drug showed a defined melting point of $218^{\circ} \mathrm{C}$ and the lack of this prominent peak in the thermograms for all EHD processed coatings suggests that TM was now encapsulated in amorphous form in the polymeric matrix as opposed to in its original crystalline form (Rasekh, Ahmad et al. 2017, Sayed, Karavasili et al. 2018). The similar melting points for the broad endotherms of F1F6 labelled in figure $6.4\left(125^{\circ} \mathrm{C}-129^{\circ} \mathrm{C}\right)$ are lower than the raw composite $\left(131^{\circ} \mathrm{C}\right)$; highlighting $\mathrm{TM}$ was evenly distributed throughout the coatings. Thermal glass transitions $\left(T_{g}\right)$ can be detected in these thermograms between $59^{\circ} \mathrm{C}$ and $77^{\circ} \mathrm{C}$ as a result of the base polymer materials. Due to the amorphous nature of PVP and PNIPAM, there is a temperature threshold at which they will transform from amorphous state to a part rubber part glass state. Here, it was difficult to ascertain the exact $T_{\mathrm{g}}$ when incorporating chitosan.

Chitosan is semi-crystalline as a result of strong inter- and intra-molecular bonds and its amorphous nature is due to the heterocyclic units. When heated to temperatures lower than its degradation temperature, changes in heat capacity/flow are too small to be distinguished (Wan, Lu et al. 2009). Additionally, this could be due to water or moisture forming intermolecular hydrogen bonds and acting as a plasticizer for chitosan (Sarwar, Katas et al. 2015). The weak $T_{g}$ also suggests the initial atomised coatings were predominantly amorphous to begin with which is as predicted with PVP and PNIPAM making up a proportion of these coatings.

The inclusion of chitosan in the formulations also resulted in an extra exothermic event in each thermograms (F1-F6). Chitosan possesses few crystalline regions due to high degree of acetylation and therefore goes through thermal degradation without melting; highlighted by the absence of melting endotherm of chitosan in Figure 6. The exothermic peaks between $263^{\circ} \mathrm{C}$ and $267^{\circ} \mathrm{C}$ (depending on chitosan concentration) are most likely due to the thermal decomposition of chitosan (Corazzari, Nisticò et al. 2015, Bizarria, d'Avila et al. 2014, Fei, Yu et al. 2016). The formation of 2 peaks here further confirms the presence of chitosan as solid particles. As mentioned in previous discussion about DSC thermograms, single endotherms confirm that the raw materials were not compromised and were acting as one system. Here, the presence of the exotherm responsible for the crystallisation of chitosan indicates chitosan was acting independent to the EHD processed coating.

\section{Contact Angle Analysis}


Figure 7 shows digital images of the distilled water droplet on the sample and how it dissipated over time. Figure 8 shows the contact angle (CA) analysis on the atomised coatings on the contact lenses $\mathrm{PE}$-free and chitosan-free coatings (Composite-TM) showed a high initial CA at $126.27^{\circ}$. Upon inclusion of borneol, the initial contact angle was found to be $71.5^{\circ}$ with almost 2 -fold reduction compared to the composite-TM samples. Here, the introduction of an excipient used primarily as a PE, was also found to act as a surface active agent; lowering the surface tension and improving spreadability of liquid droplet on the fibrous coatings. Regardless of chitosan's hydrophilic nature, the initial CA of the formulations containing both borneol and chitosan had increased to $96.70^{\circ}, 91.21^{\circ}$ and $91.36^{\circ}$ for $\mathrm{F} 1$, F2 and F3, respectively. This increase in CA could be attributed to the incorporation of solid particles of chitosan; the particles may act as an additional barrier, which may fill voids and pore between polymeric matrix and chitosan (Kim, Kim et al. 2013). Therefore, the water droplet has to penetrate through both the chitosan as well as the polymeric matrix of PVP and PNIPAM.

The water droplet introduced to the composite-TM atomised coatings completely dissipated within 30 mins while droplet placed on F0 samples completely spread within 20 seconds; highlighting the role of borneol as a surface active agent and helping increase the hydrophilicity of the coatings. Incorporating chitosan into formulations containing borneol increased the time required for the water droplet to spread on the coatings. The concentration of chitosan apparently affected CA over time; the higher the concentration, the longer it took for the water droplet to completely spread. This increased period of time could also be due to the increased density of the sample (as a result of the increased concentration). This increase in density can cause particle agglomeration and due to this air can become trapped between the particles; creating a new interface and hindering water penetration and spreading.

Formulations containing no PE but various concentrations of chitosan showed some interesting results. The absence of borneol showed to increase initial CA of F4, F5 and F6 to higher than that found with composite-TM samples. The higher the concentration of chitosan, the higher the initial CA. F4 and F5 required 7 minutes for the water droplet to spread on whilst F6 took 8 minutes on average. These timings are twice as longer than those with borneol and chitosan are ( 3 to 4 minutes). This change in water spreading may possibly promote better adsorption of the coatings onto the hydrophilic contact lenses.

\section{In Vitro Drug Release and Kinetics}

\section{In Vitro Drug Release}


Figure 9 shows the in vitro release of TM from all 6 atomised coatings alongside PE free atomised coatings and chitosan-free coatings. The release from PE-free coatings demonstrated a biphasic profile as previously seen in earlier studies (Mehta et al 2017), with approximately 67\% of the encapsulated drug being released after 24 hours. F1 to F6 demonstrated triphasic release profiles; with a slow and gradual initial release phase as opposed to an initial burst release seen with composite-TM and F0. The maximum amount released after 10 minutes was only $9.8 \%$ with F1 and F5; contradicting what was found with PE free (47.5\%) and chitosan free sample (14.15\%). This delay in drug release could be due to drug diffusion being hindered by the barrier of solid chitosan particles. As discussed with contact angle analysis, these particles fill the pores and voids in the coatings matrix; reducing the spatial environment available for the drug molecule to diffuse out.

Another probable reason for this delay in drug release could be attributed to the very high encapsulation efficiency achieved for all 6 formulations. Almost all the drug was trapped within the polymeric matrix (with hardly any surface associated drug); therefore this matrix must swell or dissolve before drug release can occur. Furthermore, chitosan either prevents or delays the release medium (PBS) from entering the polymeric matrix.

The two subsequent release phases are due to the polymer base of PVP and PNIPAM. The $2^{\text {nd }}$ release phase is due to the eventual dissolution of PVP and breakdown of PNIPAM chains whilst the $3^{\text {rd }}$ release phase is due to polymer erosion. As seen with DSC analysis, the thermograms indicated a thermal transition of polymer from the rubbery to glassy state. This could provide an explanation for the sustained release of TM observed in phases 2 and 3.

Some of the drug may be entrapped within the crystalline regions of the polymer (chitosan); hence is isolated from the release medium in the donor compartment. Only upon polymer degradation can the trapped drug be released; resulting in gradual sustained release forming the $3^{\text {rd }}$ release phase (Natu, de Souza et al. 2011).

Fulĝencio et al developed mucoadhesive chitosan films loaded with TM and achieved $85 \%$ drug release over 2 weeks (Fulgencio, Bretas Viana et al. 2012). Whilst this release was successfully prolonged, the practicality of such a device is questionable. Whilst the research presented here is mainly a proof of concept; the use of contact lenses has already been proven successful in vision correction and for cosmetic purposes. Furthermore, over $89 \%$ of drug was delivered within 24 hours; a much more convenient dosing period for the patient. Aggarwal et al used chitosan and nanocarrier niosomes to assess their combined ability to enhance TM release (Aggarwal, Kaur 2005). They found that by coating 
the niosomes with chitosan, drug release was significantly prolonged from $91 \%$ in 2 hours to $40.43 \%$ over 10 hours.

Here, the concentration of chitosan did significantly affect the total cumulative percentage release $(p=0.0276)$, albeit only slightly. Formulations containing $1 \% \mathrm{w} / \mathrm{v}$ chitosan ( $\mathrm{F} 1$ and $\mathrm{F} 4$ ) release $89.7 \%$ and $90.78 \% \mathrm{TM}$, respectively, with this decreasing to $88.16 \%$ and $78.05 \%$ for F3 and $\mathrm{F} 6 \mathrm{~F} \% \mathrm{w} / \mathrm{v}$ chitosan), respectively. Increasing the concentration of chitosan suggests a greater proportion of solid particles being dispersed throughout the atomised matrix; further delaying drug diffusion.

\section{In Vitro Probe Release}

Rhodamine B was utilised as a model drug to establish whether the atomised coatings remain on the surface of the contact les whilst releasing drug. Figure $\mathbf{1 0}$ shows the release of rhodamine $B$ from the atomised coatings on the contact lenses and into PBS $\left(\mathrm{pH} 7.4 ; 37^{\circ} \mathrm{C}\right)$. The atomised coatings were composed of the same materials as stated in Table 1 however Rhodamine B replaced TM. The fluorescing of the contact lens at the sampled time points indicates the coatings is still there and has not detached from the lens upon introduction to the release medium whilst the probe release into PBS found to mirror the results obtained with in vitro drug release.

\section{Drug Release Kinetics}

To elucidate the drug release mechanism, various empirical kinetic models (zero-order, first-order, Hixson-Cromwell, Higuchi and Korsmeyer-Peppas) were applied to the in vitro release data points. Table 3 collates the regression coefficients for the first four models with Table 4 summarising the important parameters derived from the Korsmeyer-Peppas model.

All 6 formulations demonstrated poor fit to the zero-order model; with $\mathrm{R}^{2}$ values ranging from 0.5869 to 0.8363 . When fitted to first order release model, high $\mathrm{R}^{2}$ values $(0.8178-0.9930)$ were obtained; indicating that TM release was dependent on the initial drug concentration. The poor fit of data (low $\mathrm{R}^{2}$ values) to the Hixson-Cromwell model suggested that TM was not being released via dissolution. This, however, does not confirm drug release was via diffusion. Due to this, Higuchi and KorsmeyerPeppas models were applied. $\mathrm{R}^{2}$ values above 0.95 derived from the Higuchi model indicates that the drug release is diffusion based. The high $\mathrm{R}^{2}$ values from Higuchi model were obtained for F1 and F6 (0.9921 and 0.9707, respectively) suggesting that TM was released from the atomised coatings via Fickian Diffusion; (Higuchi 1963, Siepmann, Peppas 2011). Formulations F2-F5 had R² values ranging between 0.8807 and 0.9388 ; suggesting a non-Fickian diffusion mechanism. This is mirrored by the $n$ 
values calculated from the Korsmeyer-Peppas model. F1 and F6 had $\mathrm{n}$ values of 0.5399 and 0.5609 , which again indicate Fickian diffusion. F2-F5 had values that suggested both diffusion and swelling; the release was time dependent (Korsmeyer, Gurny et al. 1983, Riger, Peppas 1987).

One thing to note here is the effect of chitosan concentration. As the concentration of chitosan increased, the release mechanism changed from Fickian Diffusion (1\%w/v chitosan, F1) to non-Fickian diffusion using ( $5 \% \mathrm{w} / \mathrm{v}$ chitosan, $\mathrm{F} 3)$.

\section{Biological Evaluation of Atomised Coatings}

Any formulations that are to come in contact with the eye must be biocompatible and as such should be well tolerated by the cornea. If the corneal epithelium is compromised, the cornea can no longer exert its protective barrier functions; allowing foreign bodies to enter (Abdelkader, Pierscionek et al. 2015, Wilson, Ahearne et al. 2015). BCOP testing ascertains that the materials used do not compromise corneal epithelium integrity. Figure $\mathbf{1 0}$ reveals how freshly excised bovine corneas responded when treated with F3, F8 and a range of controls.

Saline (negative control) showed no signs of toxicity (which can be visually observed as no change in opacity of the cornea) (figure 10a, f)). Contrasting this is the application of either acetone (mildly positive control) or $\mathrm{NaOH}$ (strong positive control). Treating the cornea with acetone showed a weakintensity cloudy region which is more prominent upon staining and examining under the blue cobalt fluorescent light (figure $\mathbf{1 0 g}$ and $\mathrm{h}$ ). This permeation of sodium fluorescein through the cornea indicates a compromised corneal epithelium as a result of interaction with lipids in the epithelial cell membrane (Maurer, Molai et al. 2001). $\mathrm{NaOH}$ was utilised here to demonstrate the effect of strong irritants on the cornea. $\mathrm{NaOH}$ has the ability to initiate saponification of fatty acids present in corneal epithelial cells; disrupting the entirety of the epithelial layer (Reim, Schrage et al. 2001). This in turn increases the permeability of the cornea to foreign bodies. Figure $10 \mathrm{c}$ and $\mathrm{h}$ show the severe, evident damage of the cornea which is visible even without the use of the blue cobalt filtered light.

With respect to testing the formulations used in this study, the only changing variables were the presence of borneol and the concentrations of chitosan used. Therefore, only F3 (borneol and 5\%w/v chitosan) and F8 ( $5 \% \mathrm{w} / \mathrm{v}$ chitosan) were tested. If these formulations were to show signs of ocular toxicity, all other formulations would be tested to identify if lower concentrations of chitosan would be better tolerated. The staining of F3 and F6 treated bovine corneas showed no signs visual opacification under natural light (figure 10d and e) and no indication of fluorescein staining (figure $10 \mathrm{i}$ and $\mathrm{j}$ ) ; indicting that these formulations are well tolerated by the cornea.. 


\section{Conclusion}

The research presented here demonstrated how EHDA could be effective in modifying polymeric formulations to modulate the release of TM and potentially promote better absorption through the cornea without compromising corneal tolerability. The incorporation of chitosan into the atomised coatings produced particulate structures (as opposed to the fibres produced with formulations without chitosan). Subject to chitosan concentration, a wide range of particle size distributions were derived for each formulation. Thermal analysis confirmed TM was continually being encapsulated in the amorphous form and that chitosan was present as solid particles; as confirmed by the occurrence of an exotherm at $\sim 260^{\circ} \mathrm{C}$. The critical assessment of the effectiveness of chitosan (in vitro/ex vivo) revealed that the oligosaccharide to act successfully to increase TM release by up to $23 \%$ more than composite-TM coatings and up to $11 \%$ from borneol-loaded coatings (F0). This work is the first of its kind; utilising an already successful device and combining it with an engineering process that has shown great potential in the drug delivery remit. The work presented here has potentially opened avenues for further investigations in a field that requires refined treatment protocols to address unmet patient compliance needs, characteristic of conventional eye drops. .

\section{References}

ABDELKADER, H., PIERSCIONEK, B., CAREW, M., WU, Z. and ALANY, R.G., 2015. Critical appraisal of alternative irritation models: three decades of testing ophthalmic pharmaceuticals. Br Med Bull, -, pp. 1-13. 
AGGARWAL, D. and KAUR, I., 2005. Improved pharmacodynamics of timolol maleate from a mucoadhesive niosomal ophthalmic drug delivery system. International journal of pharmaceutics, 290(1-2), pp. 155-159.

AGRAHARI, V., MANDAL, A., AGRAHARI, V., TRINH, H.M., JOSEPH, M., RAY, A., HADJI, H., MITRA, R., PAL, D. and MITRA, A.K., 2016. A comprehensive insight on ocular pharmacokinetics. Drug Delivery and Translational Research, 6(6), pp. 735-754.

AL-KINANI, A.A., ZIDAN, G., ELSAID, N., SEYFODDIN, A., ALANI, A.W.G. and ALANY, R.G., 2018. Ophthalmic gels: Past, present and future. Advanced Drug Delivery Reviews,126, pp 113-126.

ATES, M., KAYNAK, M.S. and SAHIN, S., 2016. Effect of permeability enhancers on paracellular permeability of acyclovir. Journal of Pharmacy and Pharmacology, 68(6), pp. 781-790.

BENEDIKTSDOTTIR, B.E., BALDURSSON, O. and MASSON, M., 2014. Challenges in evaluation of chitosan and trimethylated chitosan (TMC) as mucosal permeation enhancers: From synthesis to in vitro application. Journal of Controlled Release, 173, pp. 18-31.

BHATTARAI, R.S., DAS, A., ALZHRANI, R.M., KANG, D., BHADURI, S.B. and BODDU, S.H.S., 2017. Comparison of electrospun and solvent cast polylactic acid (PLA)/polyvinyl alcohol) (PVA) inserts as potential ocular drug delivery vehicles. Materials Science \& Engineering CMaterials for Biological Applications, 77, pp. 895-903.

BIZARRIA, M.T.M., D'AVILA, M.A. and MEI, L.H.I., 2014. Non-Woven Nanofiber Chitosan/peo Membranes obtained by Electrospinning. Brazilian Journal of Chemical Engineering, 31(1), pp. 57-68.

CHOUGULE, M.B., PATEL, A.R., PATLOLLA, R., JACKSON, T. and SINGH, M., 2014. Epithelial transport of Noscapine across cell monolayer and influence of absorption enhancers on in vitro permeation and bioavailability: implications for intestinal absorption. Journal of drug targeting, 22(6), pp. 498-508.

CORAZZARI, I., NISTICÒ, R., TURCI, F., FAGA, M.G., FRANZOSO, F., TABASSO, S. and MAGNACCA, G., 2015. Advanced physico-chemical characterization of chitosan by means of TGA coupled on-line with FTIR and GCMS: Thermal degradation and water adsorption capacity.

DI COLO, G., BURGALASSI, S., ZAMBITO, Y., MONTI, D. and CHETONI, P., 2004. Effects of different $\mathrm{N}$-trimethyl chitosans on in vitro/in vivo ofloxacin transcorneal permeation. Journal of pharmaceutical sciences, 93(11), pp. 2851-2862.

DUTTAGUPTA, D.S., JADHAV, V.M. and KADAM, V.J., 2015. Chitosan: A Propitious Biopolymer for Drug Delivery. Current Drug Delivery, 12(4), pp. 369-381.

FEI, X., YU, M., ZHANG, B., CAO, L., YU, L., JIA, G. and ZHOU, J., 2016. The fluorescent interactions between amphiphilic chitosan derivatives and water-soluble quantum dots. 
FULGENCIO, G.D.O., BRETAS VIANA, F.A., RIBEIRO, R.R., YOSHIDA, M.I., FARACO, A.G. and CUNHA-JUNIOR, A.D.S., 2012. New Mucoadhesive Chitosan Film for Ophthalmic Drug Delivery of Timolol Maleate: In Vivo Evaluation. Journal of Ocular Pharmacology and Therapeutics, 28(4), pp. 350-358.

GAUDANA, R., ANANTHULA, H.K., PARENKY, A. and MITRA, A.K., 2010. Ocular Drug Delivery. Aaps Journal, 12(3), pp. 348-360.

GIULIANI, A., BALDUCCI, A.G., ZIRONI, E., COLOMBO, G., BORTOLOTTI, F., LORENZINI, L., GALLIGIONI, V., PAGLIUCA, G., SCAGLIARINI, A., CALZA, L. and SONVICO, F., 2018. In vivo nose-to-brain delivery of the hydrophilic antiviral ribavirin by microparticle agglomerates. Drug delivery, 25(1), pp. 376-387.

HIGUCHI, T., 1963. Mechanism of sustained medication. Theoretical Analysis of rate of release of solid drugs dispersed in solid matrices. J. Pharm. Sci, 84, pp. 1464-1477.

KARATAS, A., ALGAN, A.H., PEKEL-BAYRAMGIL, N., TURHAN, F. and ALTANLAR, N., 2016. Ofloxacin Loaded Electrospun Fibers for Ocular Drug Delivery: Effect of Formulation Variables on Fiber Morphology and Drug Release. Current Drug Delivery, 13(3), pp. 433-443.

KIM, J., KIM, E. and KIM, S.S., 2013. Micro-nano hierarchical superhydrophobic electrospraysynthesized silica layers. Journal of colloid and interface science, 392, pp. 376-381.

KONTOGIANNIDOU, E., ANDREADIS, D.A., ZOGRAFOS, A.L., NAZAR, H., KLEPETSANIS, P., VAN DER MERWE, S.M. and FATOUROS, D.G., 2017. Ex vivo buccal drug delivery of ropinirole hydrochloride in the presence of permeation enhancers: the effect of charge. Pharmaceutical development and technology, 22(8), pp. 1017-1021.

KORSMEYER, R.W., GURNY, R., DOELKER, E., BURI, P. and PEPPAS, N.A., 1983. Mechanisms of solute release from porous hydrophilic polymers. Int.J.Pharm., 15, pp. 25-35.

KUMAR, A., VIMAL, A. and KUMAR, A., 2016. Why Chitosan? From properties to perspective of mucosal drug delivery. International journal of biological macromolecules, 91, pp. 615622.

LANCINA, MICHAEL G.,,III, SINGH, S., KORNPELLA, U.B., HUSAIN, S. and YANG, H., 2017. Fast Dissolving Dendrimer Nanofiber Mats as Alternative to Eye Drops for More Efficient Antiglaucoma Drug Delivery. Acs Biomaterials Science \& Engineering, 3(8), pp. 1861-1868.

LI, X., WANG, X., YU, D.G., YE, S., KUANG, Q., YI, Q. and YAO, X., 2012. Electrospun BorneolPVP Nanocomposite. J. Nanomater, 2012, pp. 1-8.

MAHALING, B. and KATTI, D.S., 2016. Understanding the influence of surface properties of nanoparticles and penetration enhancers for improving bioavailability in eye tissues in vivo.

MAHER, S., MRSNY, R.J. and BRAYDEN, D.J., 2016. Intestinal permeation enhancers for oral peptide delivery. Advanced Drug Delivery Reviews, 106, pp. 277-319. 
MAURER, J., MOLAI, A., PARKER, R., LI, L., CARR, G., PETROLL, W., CAVANAGH, H. and JESTER, J., 2001. Pathology of ocular irritation with acetone, cyclohexanol, parafluoroaniline, and formaldehyde in the rabbit low-volume eye test. Toxicologic pathology, 29(2), pp. 187199.

MEHTA, P., HAJ-AHMAD, R., AL-KINANI, A., ARSHAD, M.S., CHANG, M.W., ALANY, R.G. and AHMAD, Z., 2017a. Approaches in topical ocular drug delivery and developments in the use of contact lenses as drug-delivery devices. Ther. Deliv., 8, pp. 521-541.

MEHTA, P., AL-KINANI, A.A., HAJ-AHMAD, R., ARSHAD, M.S., CHANG, M., ALANY, R.G. and AHMAD, Z., 2017. Electrically atomised formulations of timolol maleate for direct and ondemand ocular lens coatings. European Journal of Pharmaceutics and Biopharmaceutics, 119, pp. 170-184.

MEHTA, P., HAJ-AHMAD, R., RASEKH, M., ARSHAD, M.S., SMITH, A., VAN DER MERWE, S.M., LI, X., CHANG, M. and AHMAD, Z., 2017b. Pharmaceutical and biomaterial engineering via electrohydrodynamic atomization technologies. Drug discovery today, 22, pp. 157-165.

MEHTA, P., JUSTO, L., WALSH, S., ARSHAD, M.S., WILSON, C.G., O'SULLIVAN, C.K., MOGHIMI, S.M., VIZIRIANAKIS, I.S., AVGOUSTAKIS, K., FATOUROS, D.G. and AHMAD, Z., 2015. New platforms for multi-functional ocular lenses: engineering double-sided functionalized nanocoatings. Journal of drug targeting, 23(4), pp. 305-310.

MERLINI, C., BARRA, G.M.O., ARAUJO, T.M. and PEGORETTI, A., 2014. Electrically pressure sensitive poly(vinylidene fluoride)/polypyrrole electrospun mats. Rsc Advances, 4(30), pp. 15749-15758.

MUXIKA, A., ETXABIDE, A., URANGA, J., GUERRERO, P. and DE LA CABA, K., 2017. Chitosan as a bioactive polymer: Processing, properties and applications.

NATU, M.V., DE SOUZA, H.C. and GIL, H., 2011. Electrospun Drug-Eluting Fibers for Biomedical Applications. Active Implants and Scaffolds for Tissue Regeneration, 8, pp. 57-85.

RASEKH, M., AHMAD, Z., CROSS, R., HERNANDEZ-GIL, J., WILTON-ELY, J.D.E.T. and MILLER, P.W., 2017. Facile Preparation of Drug-Loaded Tristearin Encapsulated Superparamagnetic Iron Oxide Nanoparticles Using Coaxial Electrospray Processing. Molecular Pharmaceutics, 14(6), pp. 2010-2023.

RAVAL, N., KHUNT, D. and MISRA, M., 2018. Microemulsion-based delivery of triamcinolone acetonide to posterior segment of eye using chitosan and butter oil as permeation enhancer: an in vitro and in vivo investigation. Journal of microencapsulation, 35(1), pp. 6277.

REIM, M., SCHRAGE, N.F. and BECKER, J., 2001. Interactions between ocular surface fluid and cornea related to contact lenses. European journal of ophthalmology, 11(2), pp. 105115. 
RIGER, P.L. and PEPPAS, N.A., 1987. A simple equation for description of solute release: II. Fickian and anomalous release from swellable devices. J. Controlled Release, , pp. 37-42.

RODRIGUEZ, I., ANTONIO VAZQUEZ, J., PASTRANA, L. and KHUTORYANSKIY, V.V., 2017. Enhancement and inhibition effects on the corneal permeability of timolol maleate:

Polymers, cyclodextrins and chelating agents. International journal of pharmaceutics, 529(12), pp. 168-177.

RUPENTHAL, I.D., GREEN, C.R. and ALANY, R.G., 2011. Comparison of ion-activated in situ gelling systems for ocular drug delivery. Part 1: Physicochemical characterisation and in vitro release. International journal of pharmaceutics, 411(1-2), pp. 69-77.

SAROHA, A., PANDEY, P. and KAUSHIK, D., 2017. Development of Timolol Maleate Loaded Chitosan Nanopartices for Improved Ocular Delivery. Pharmaceutical Nanotechnology, 5(4), pp. 310-316.

SARWAR, A., KATAS, H., SAMSUDIN, S.N. and ZIN, N.M., 2015. Regioselective Sequential Modification of Chitosan via Azide-Alkyne Click Reaction: Synthesis, Characterization, and Antimicrobial Activity of Chitosan Derivatives and Nanoparticles. Plos One, 10(4), pp. UNSP e0123084.

SAYED, E., KARAVASILI, C., RUPARELIA, K., HAJ-AHMAD, R., CHARALAMBOPOULOU, G., STERIOTIS, T., GIASAFAKI, D., COX, P., SINGH, N., GIASSAFAKI, L.N., MPENEKOU, A., MARKOPOULOU, C.K., VIZIRIANAKIS, I.S., CHANG, M., FATOUROS, D.G. and AHMAD, Z., 2018. Electrosprayed mesoporous particles for improved aqueous solubility of a poorly water soluble anticancer agent: in vitro and ex vivo evaluation.

SIEPMANN, J. and PEPPAS, N.A., 2011. Higuchi Equation: Derivation, applications, use and misuse. Int.J.Pharm., 418, pp. 6-12.

TASKAR, P., TATKE, A. and MAJUMDAR, S., 2017. Advances in the use of prodrugs for drug delivery to the eye. Expert Opinion on Drug Delivery, 14(1), pp. 49-63.

WAN, Y., LU, X., DALAI, S. and ZHANG, J., 2009. Thermophysical properties of polycaprolactone/chitosan blend membranes.

WANG, J., ZHENG, H., CHANG, M.W., AHMAD, Z. and LI, J.S., 2017. Preparation of active 3D film patches via aligned fiber electrohydrodynamic (EHD) printing. Sci Rep, 7, pp. 43924.

WILSON, S.L., AHEARNE, M. and HOPKINSON, A., 2015. An overview of current techniques for ocular toxicity testing.

WU CHUN-JIE, HUANG QIN-WAN, QI HONG-YI, PING, G. and HOU SHI-XIANG, 2006.

Promoting effect of borneol on the permeability of puerarin eye drops and timolol maleate eye drops through the cornea in vitro. Pharmazie, 61(9), pp. 783-788. 
XIE, J., JIANG, J., DAVOODI, P., SRINIVASAN, M.P. and WANG, C., 2015. Electrohydrodynamic atomization: A two-decade effort to produce and process micro-/nanoparticulate materials. Chemical Engineering Science, 125, pp. 32-57.

YANG, H., XUN, Y., LI, Z., HANG, T., ZHANG, X. and CUI, H., 2009. Influence of Borneol on In Vitro Corneal Permeability and on In Vivo and In Vitro Corneal Toxicity. Journal of International Medical Research, 37(3), pp. 791-802.

ZAMANI, M., PRABHAKARAN, M.P. and RAMAKRISHNA, S., 2013. Advances in drug delivery via electrospun and electrosprayed nanomaterials. International Journal of Nanomedicine, 8, pp. 2997-3017.

ZHANG, C., YAO, Z., DING, Q., CHOI, J.J., AHMAD, Z., CHANG, M. and LI, J., 2017. Tri-Needle Coaxial Electrospray Engineering of Magnetic Polymer Yolk-Shell Particles Possessing DualImaging Modality, Multiagent Compartments, and Trigger Release Potential. Acs Applied Materials \& Interfaces, 9(25), pp. 21485-21495.

\section{Figures and tables Captions}

Table 1 Formulation composition each formulation. Each formulation contained $2.5 \% \mathrm{w} / \mathrm{v}$ PVP, $2.5 \% \mathrm{w} / \mathrm{v}$ PNIPAM and $15 \% \mathrm{w} / \mathrm{w}$ TM

Table 2 Coating Composition and drug encapsulation efficiencies for each atomised coating 
Table 3 Kinetic Models for timolol maleate release expressed by regression coefficient, $\mathrm{R}^{2}$

Table 4 Summary of Korsmeyer-Peppas model parameters for Timolol Maleate Release

Figure 1 Schematic Diagram of the EHDA system

Figure 2 SEM Images of EHD atomised a) Composite-TM, b) F0, c) F3, d) F2, e) F1, f) F6, g) F5 and h) F4

Figure 3 Size Distribution for all 6 atomised coating samples

Figure 4 FTIR analysis of pure timolol maleate, chitosan and electrohydrodynamically processed coatings

Figure 5 DSC Analysis of electrically atomised coatings with a) Formulations containing borneol and b) Formulations free of borneol

Figure 6 Digital images taken during contact angle analysis over time for a) F1, b) F2, c) F3, d) F4, e) F5, f) F6

Figure 7 Contact angle analysis over time for F1-F6 compared to composite-TM coatings and F0 coatings

Figure 8 In Vitro Cumulative TM release from electrically atomised coatings

Figure 9 In Vitro (Rhodamine B) release from atomised coatings into PBS from a) F1 and F4, b) F2 and $F 5$, c) F3 and F6

Figure 10 BCOP results of freshly excised bovine cornea. Digital Images of cornea treated with a) Saline, b) Acetone, c) $\mathrm{NaOH}$, d) F3 and e) F8. Fluorescence images of cornea under cobalt blue filter treated with f) saline, g) acetone, h) $\mathrm{NaOH}$, i) F4, j) F8 
Table 1 Formulation composition each formulation. Each formulation contained 2.5\%w/v PVP, 2.5\%w/v PNIPAM and $15 \% \mathrm{w} / \mathrm{w}$ TM 


\begin{tabular}{|c|c|c|} 
Formulation & $\begin{array}{c}\text { Borneol } \\
\text { Concentration } \\
(\% \mathbf{w} / \mathbf{v})\end{array}$ & $\begin{array}{c}\text { Chitosan } \\
\text { Concentration } \\
(\mathbf{\% w} / \mathbf{v})\end{array}$ \\
\hline \begin{tabular}{c|c|} 
Composite-TM \\
FO
\end{tabular} & 0 & 0 \\
F1 & 0.1 & 0 \\
F2 & 0.1 & 1 \\
F3 & 0.1 & 2 \\
F4 & 0.1 & 5 \\
\hline F5 & 0 & 1 \\
\hline F6 & 0 & 2 \\
\hline
\end{tabular}


Table 2 Coating composition and drug encapsulation efficiencies for each atomised coating

\begin{tabular}{|c|c|c|c|c|c|} 
Formulation & $\begin{array}{c}\text { Polymer } \\
\text { Matrix } \\
\text { (\%w/w) }\end{array}$ & $\begin{array}{c}\text { Timolol } \\
\text { Maleate }\end{array}$ & $\begin{array}{c}\text { Borneol } \\
(\mathbf{\% w} / \mathbf{w})\end{array}$ & $\begin{array}{c}\text { Chitosan } \\
(\mathbf{\% w} / \mathbf{w})\end{array}$ & $\begin{array}{c}\text { Encapsulation } \\
\text { Efficiency (\%) }\end{array}$ \\
\hline $\begin{array}{c}\text { Composite-TM } \\
\text { F0 }\end{array}$ & 89.96 & 13.04 & -- & -- & 99.7 \\
\cline { 2 - 6 } F1 & 85.47 & 12.82 & 1.71 & -- & 99.7 \\
\hline F2 & 72.99 & 10.95 & 1.46 & 14.60 & 97.93 \\
\hline F3 & 63.70 & 9.55 & 1.27 & 25.48 & 93.92 \\
\hline F4 & 46.08 & 6.91 & 0.93 & 46.08 & 90.69 \\
\hline F5 & 74 & 11.2 & -- & 14.82 & 90.45 \\
\hline F6 & 64.52 & 9.69 & -- & 25.80 & 88.80 \\
\hline & 46.51 & 6.98 & -- & 46.51 & 88.38 \\
\hline
\end{tabular}


Table 3 Kinetic Models for timolol maleate release expressed by regression coefficient, R2

\begin{tabular}{|c|c|c|c|c|} 
Formulation & Zero Order & First Order & $\begin{array}{c}\text { Hixson- } \\
\text { Cromwell }\end{array}$ & Higuchi \\
\hline \multirow{2}{*}{ F1 } & 0.8363 & 0.993 & 0.4272 & 0.9921 \\
\hline F2 & 0.7023 & 0.9217 & 0.3938 & 0.9351 \\
\hline F3 & 0.7138 & 0.9281 & 0.4130 & 0.9388 \\
\hline F4 & 0.6820 & 0.9063 & 0.3847 & 0.9178 \\
\hline F5 & 0.5869 & 0.8178 & 0.3250 & 0.8807 \\
\hline F6 & 0.7637 & 0.9301 & 0.4070 & 0.9707 \\
\hline
\end{tabular}


Table 4 Summary of Korsmeyer-Peppas model parameters for TImolol Maleate Release

$R^{2} \quad n \quad$ Mechanism of Release

\section{Formulation}

\begin{tabular}{|l|c|c|c|}
\hline F1 & 0.9474 & 0.5399 & Fickian Diffusion \\
\cline { 2 - 4 } F2 & 0.9926 & 0.6873 & Non-Fickian Diffusion \\
\hline F3 & 0.9855 & 0.7274 & Non-Fickian Diffusion \\
\hline F4 & 0.9248 & 0.7799 & Non-Fickian Diffusion \\
\hline F5 & 0.9862 & 0.48 & Non-Fickian Diffusion \\
\hline F6 & 0.9741 & 0.5609 & Fickian Diffusion \\
\hline
\end{tabular}




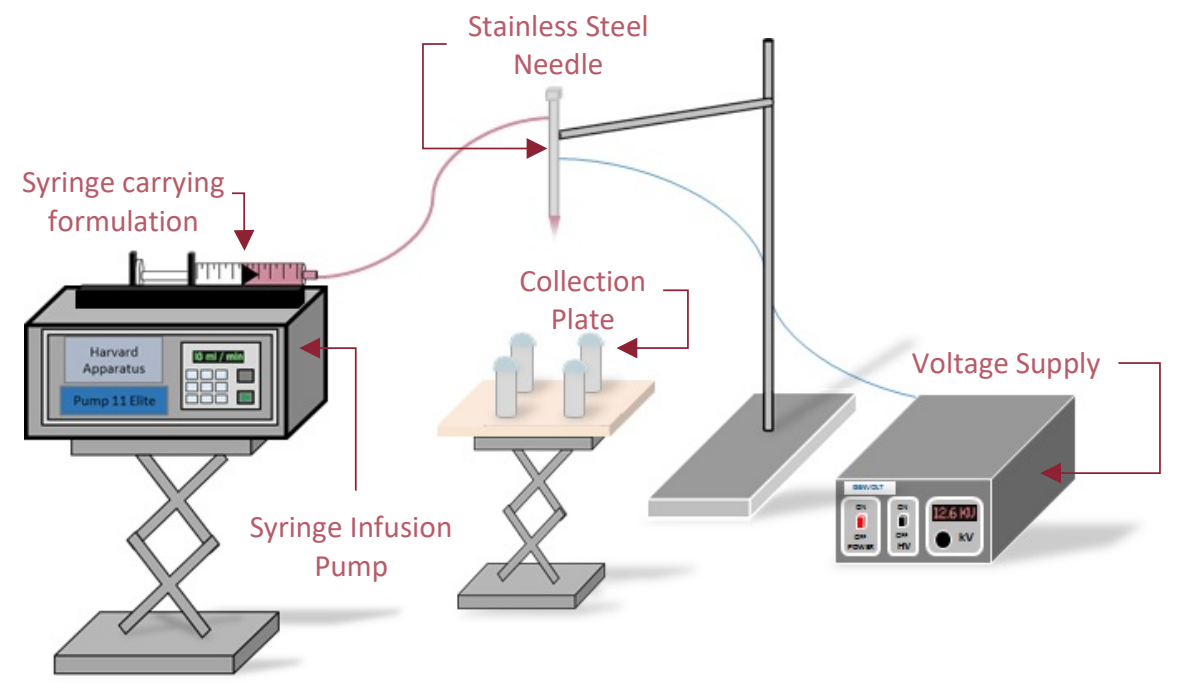

Figure 1 Schematic Diagram of the EHDA system 


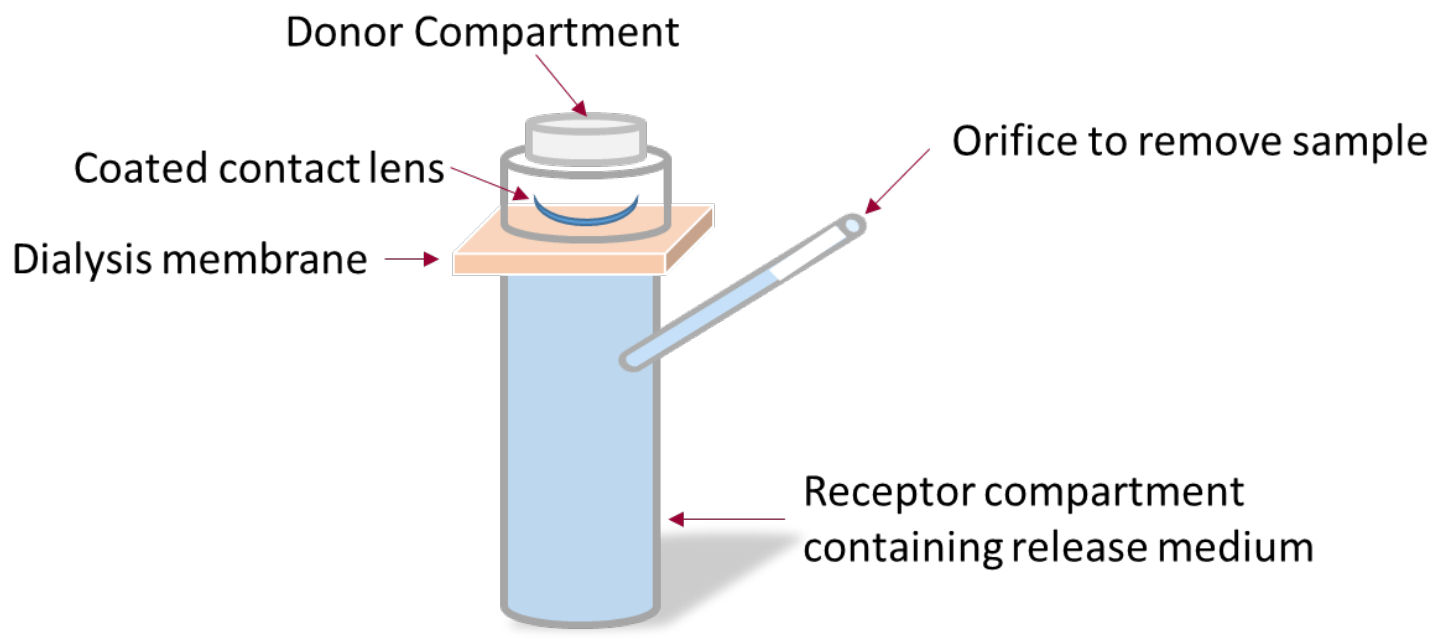

Figure $2 \mathrm{~A}$ scheme of the assembly used for drug and probe drug release studies 

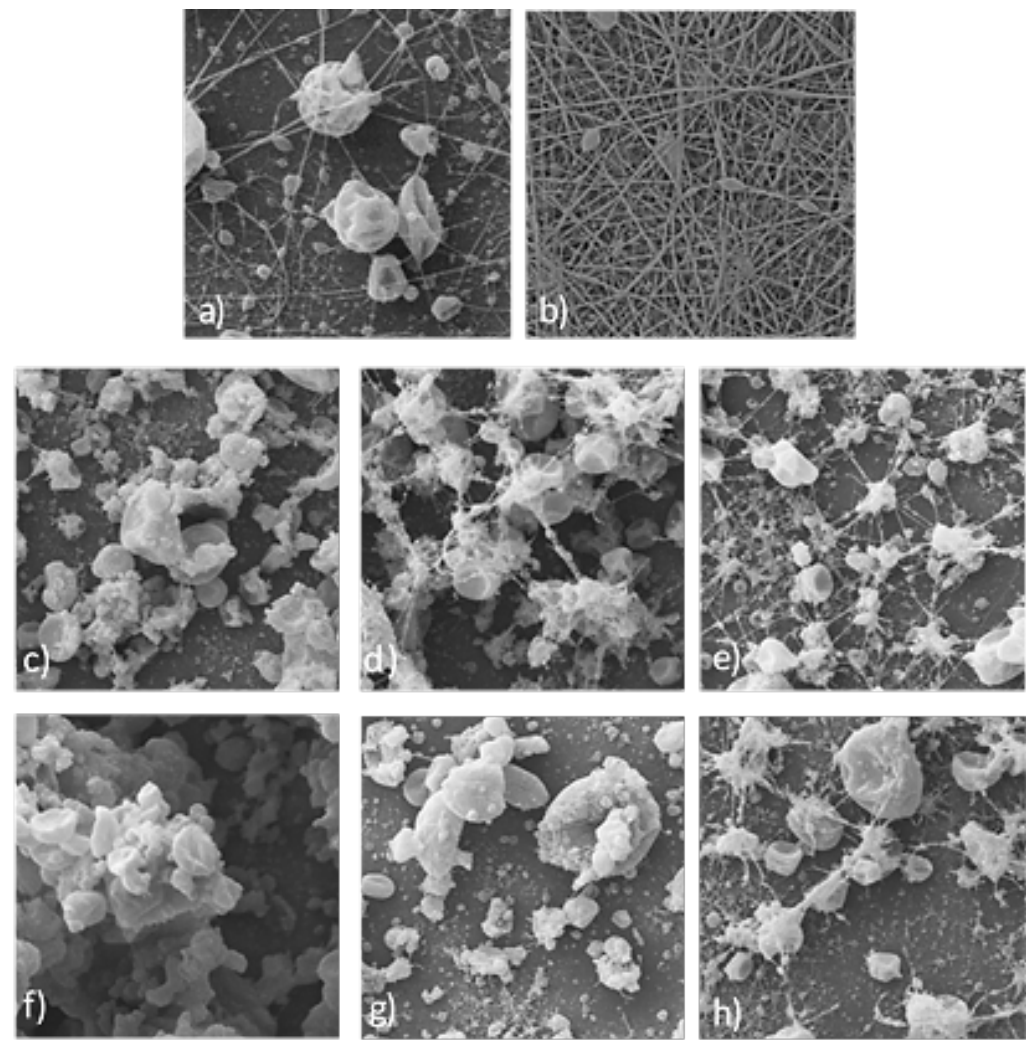

Figure 3 SEM Images of EHD atomised a) Composite-TM, b) F0, c) F3, d) F2, e) F1, f) F6, g) F5 and h) F4 


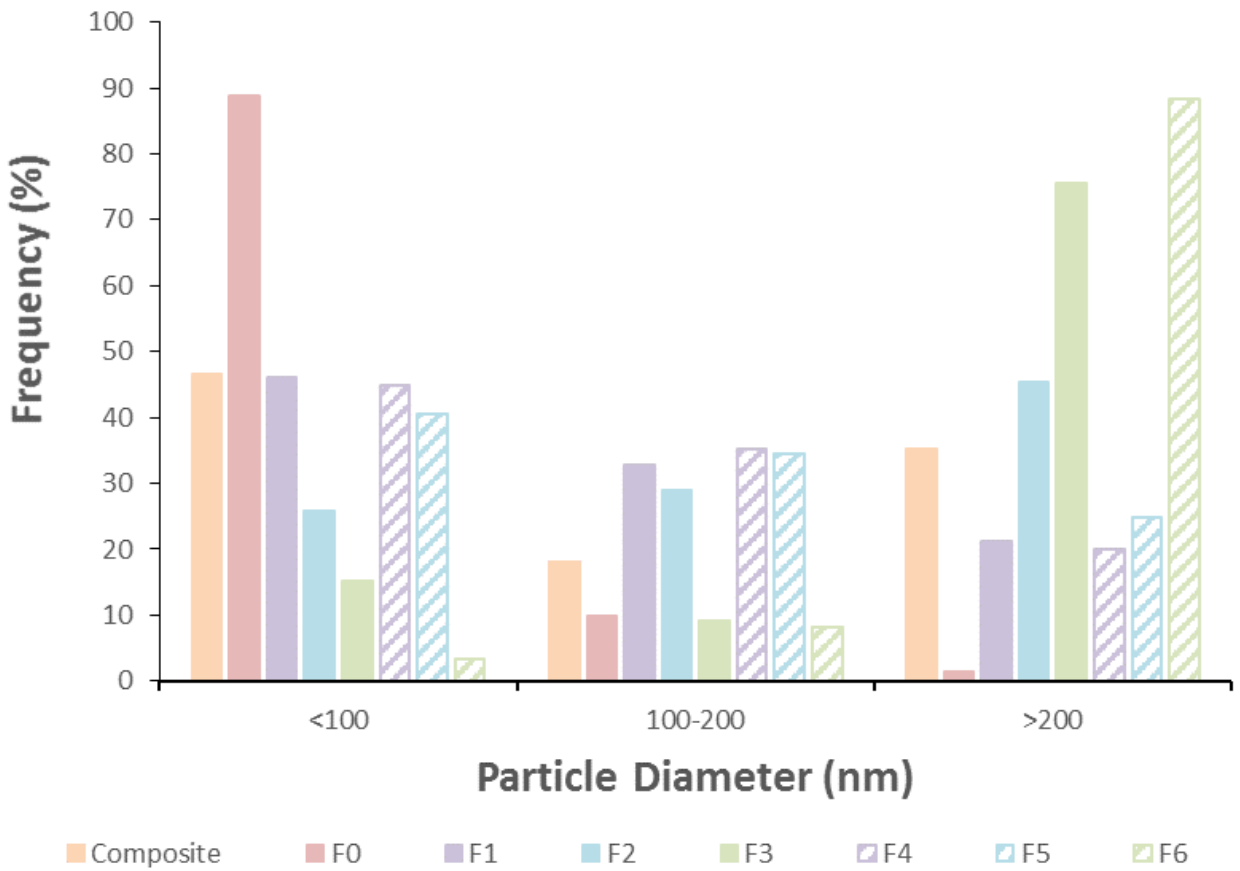

Figure 4 Size Distribution for all 6 atomised coating samples 

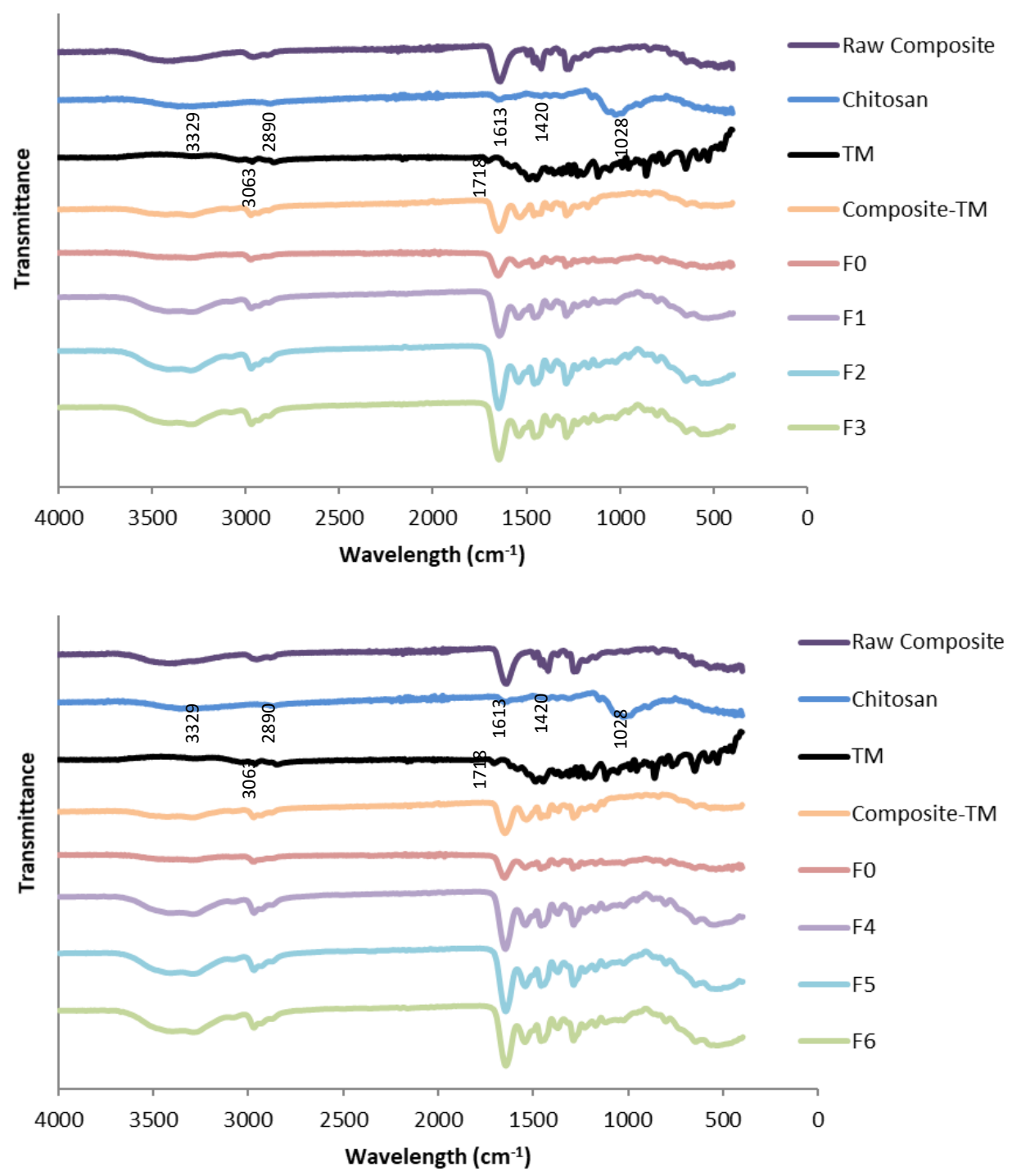

Figure 5 FTIR analysis of raw timolol maleate, chitosan and electrohydrodynamically processed coatings 

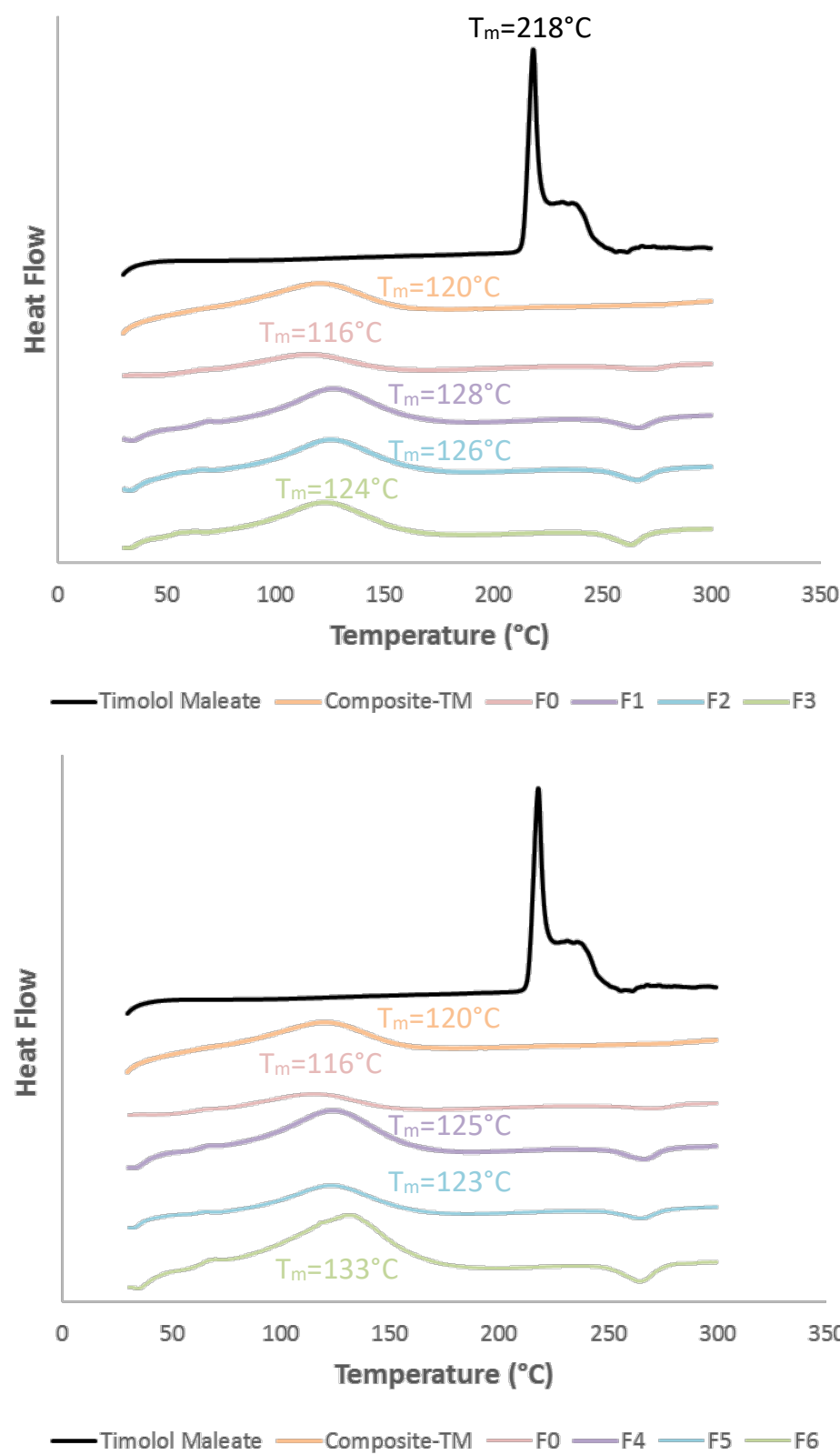

Figure 6 DSC Analysis of electrically atomised coatings with a) Formulations containing borneol and b) Formulations free of borneol 
a)

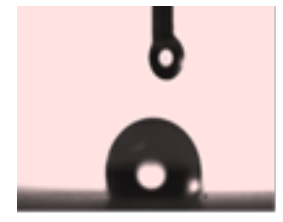

0 secs

b)

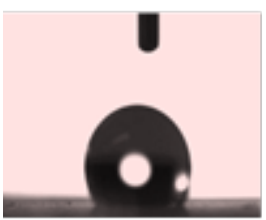

0 secs

c)

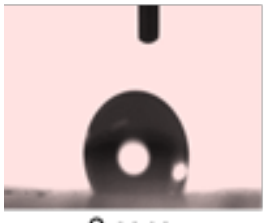

0 secs
6

d)

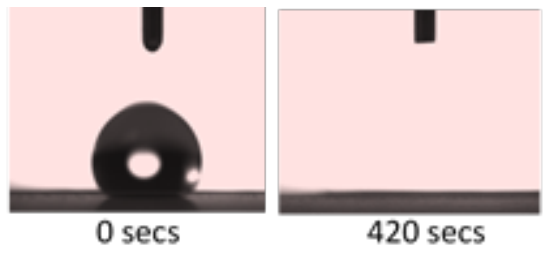

e)

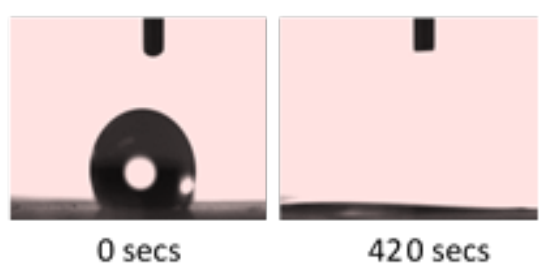

f)

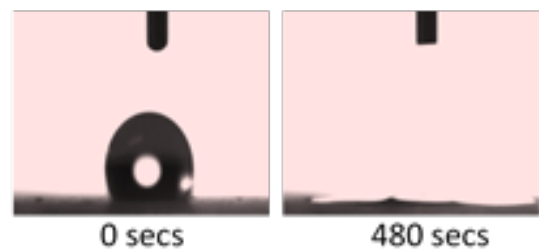

Figure 7 Digital images of distilled water droplet on the atomised coatings taken during contact angle analysis over time for a) F1, b) F2, c) F3, d) F4, e) F5, f) F6 

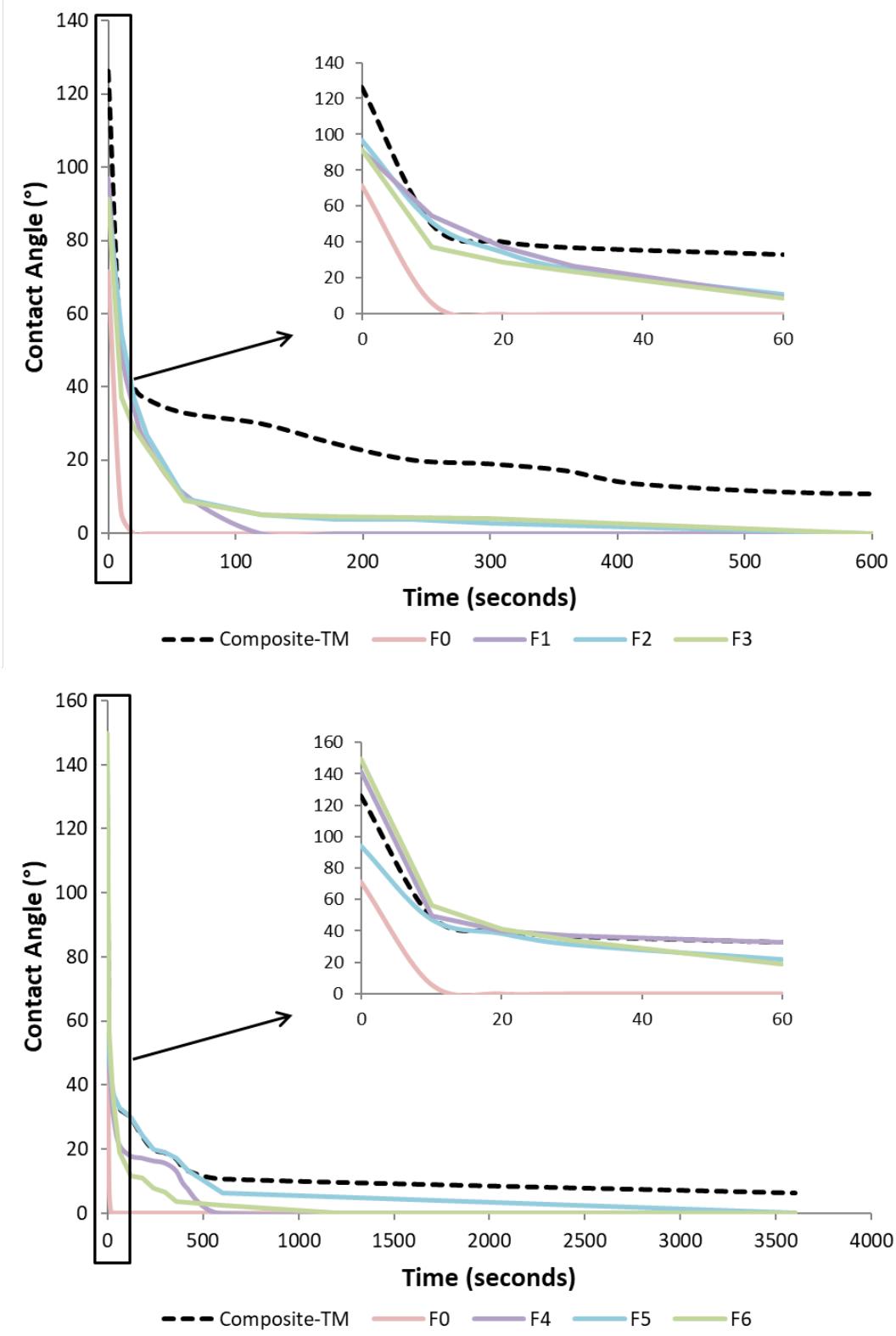

Figure 8 Contact angle analysis over time for F1-F6 compared to composite-TM coatings and F0 coatings 

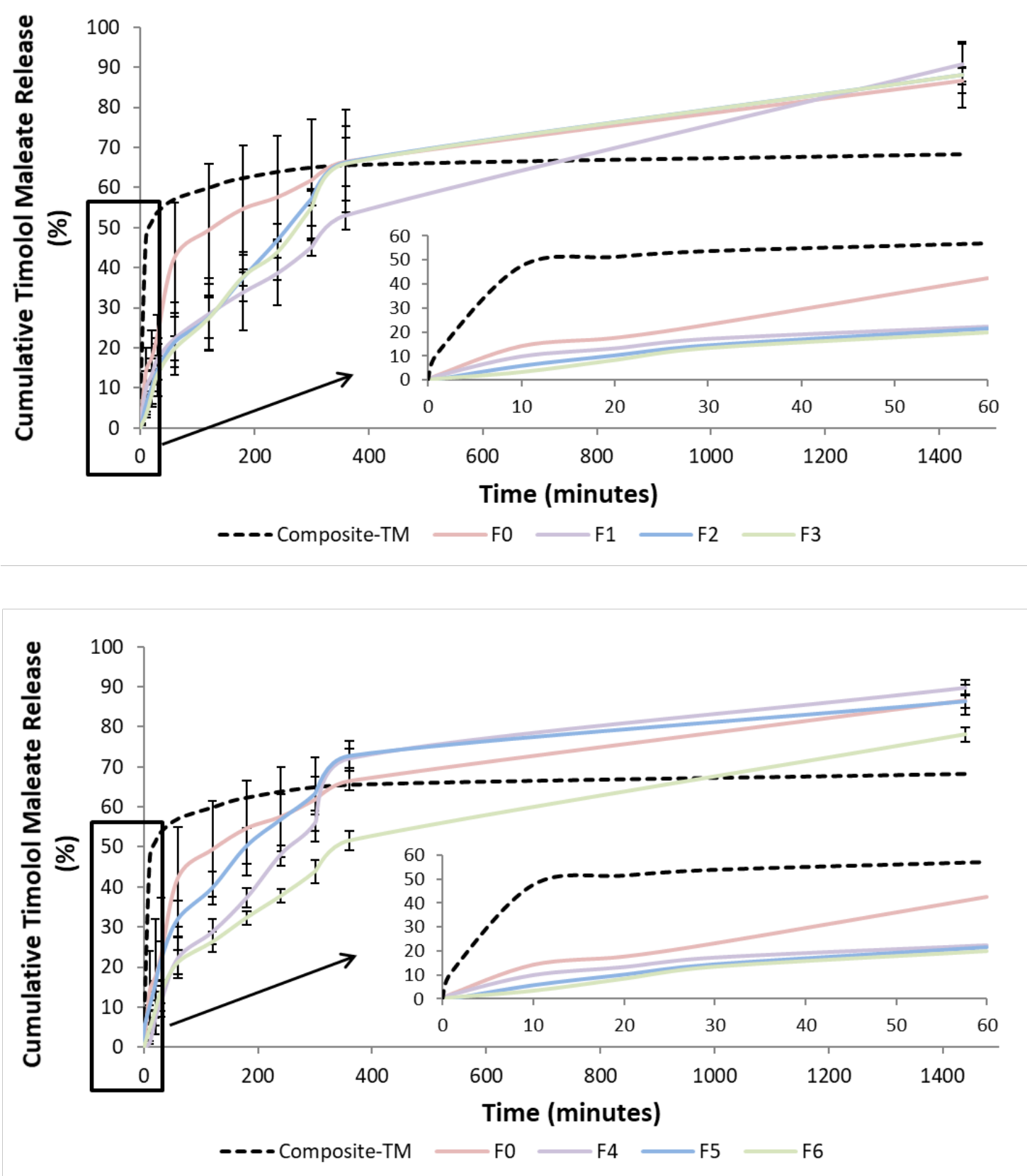

Figure 9 In Vitro cumulative TM release from electrically atomised coatings 

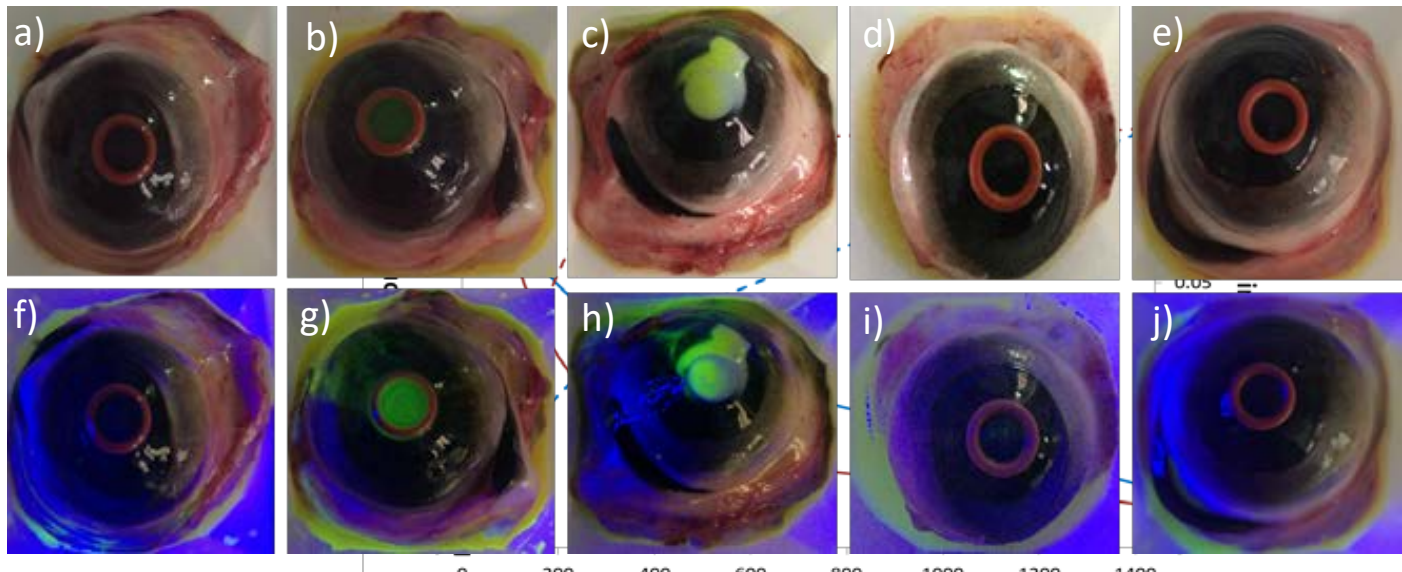

Figure 11 BCOP results of freshly excised bovine cornea. Digital Images of cornea treated with a) Saline, b) Acetone, c) $\mathrm{NaOH}$, d) F3 and e) F8. Fluorescence images of cornea under cobalt blue filter treated with f) saline, g) acetone, h) $\mathrm{NaOH}$, i) F4, j) F8

b)
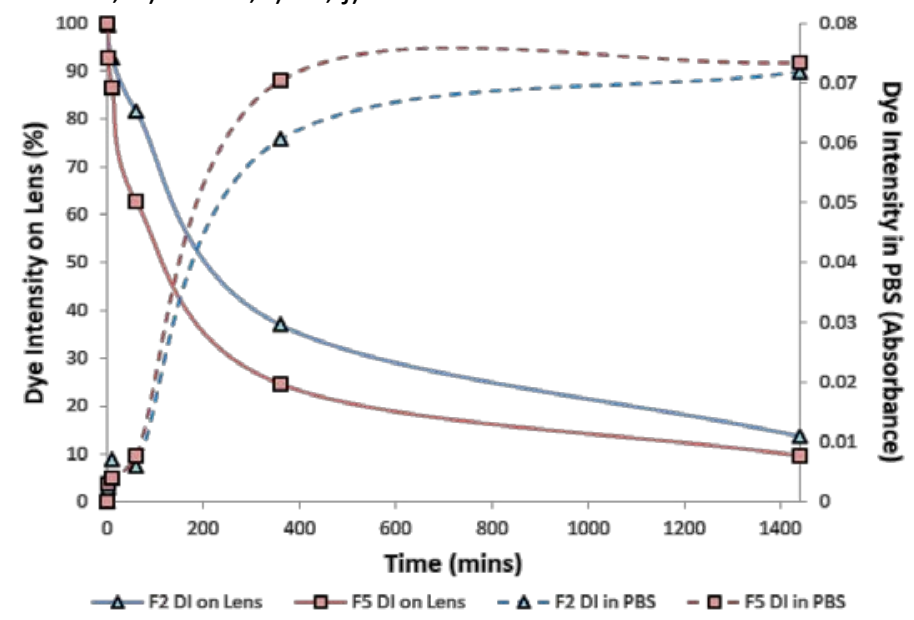

c)

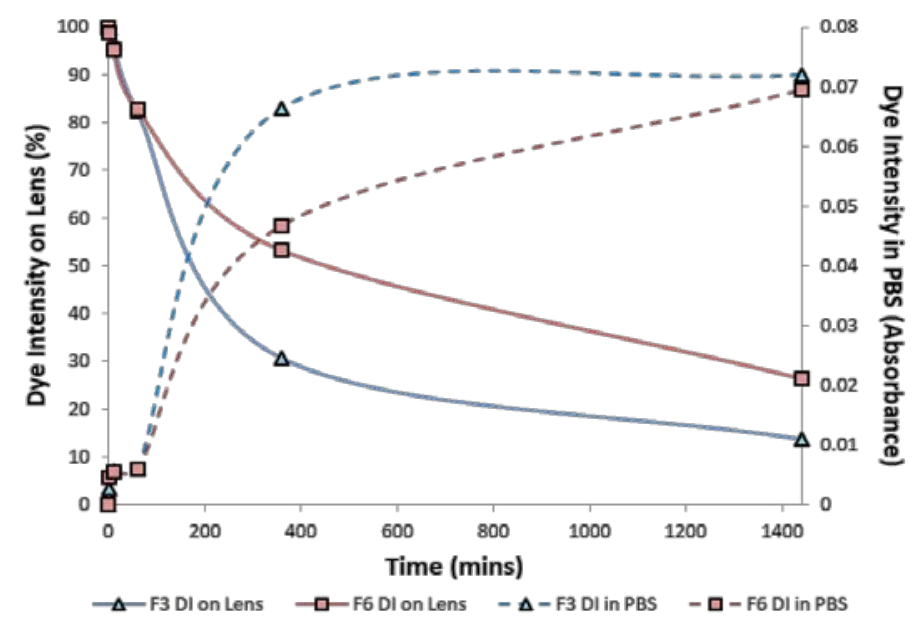

Figure 10 In Vitro probe release from atomised coatings into PBS from a) F1 and F4, b) F2 and F5, c) F3 and $\mathrm{F} 6$ 
Supplementary Data: 
S1- Timolol Maleate Calibration Curve

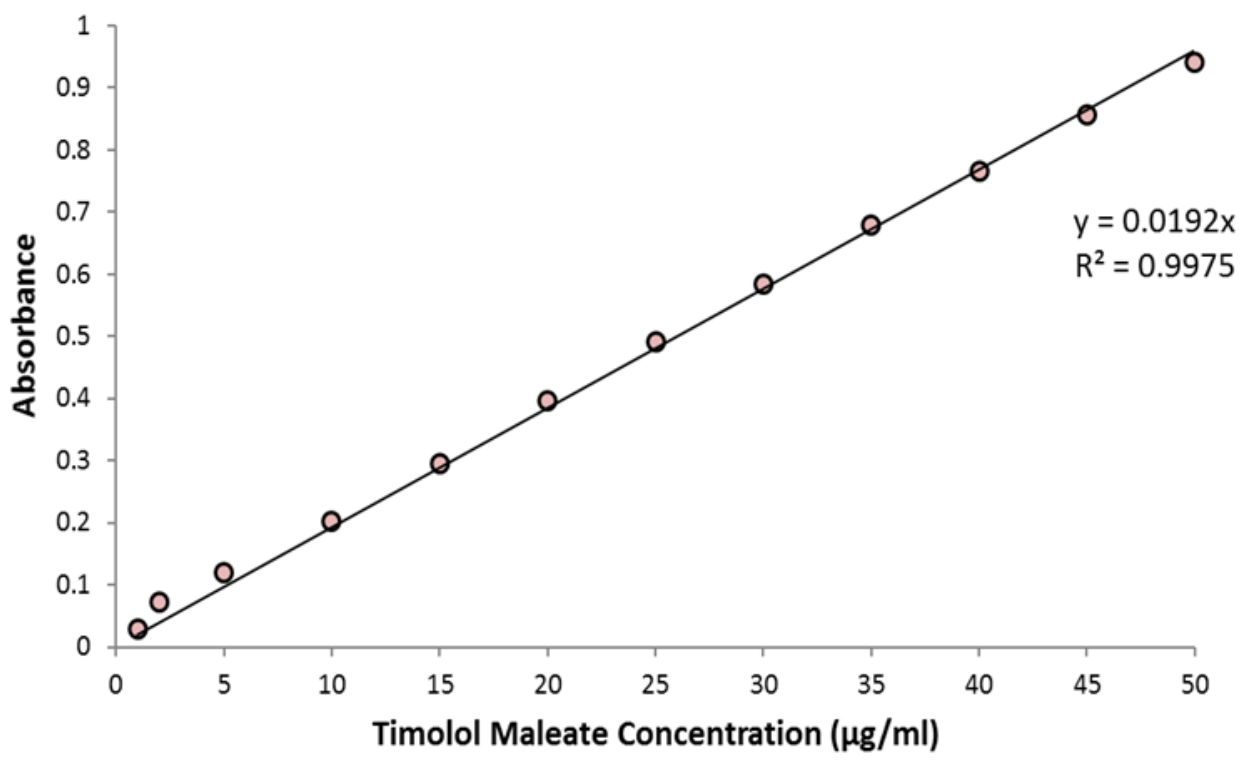

